\title{
A Chinese Herbal Decoction, Danggui Buxue Tang, Stimulates Proliferation, Differentiation and Gene Expression of Cultured Osteosarcoma Cells: Genomic Approach to Reveal Specific Gene Activation
}

\author{
Roy C. Y. Choi, ${ }^{1}$ Qiu T. Gao, ${ }^{1}$ Anna W. H. Cheung, ${ }^{1}$ Judy T. T. Zhu, ${ }^{1}$ Faye T. C. Lau, ${ }^{1}$ Jun Li, ${ }^{1}$ \\ Winnie Z. M. Li, ${ }^{1}$ Glanice K. Y. Chu, ${ }^{1}$ Ran Duan, ${ }^{1}$ Jerry K. H. Cheung, ${ }^{1}$ An W. Ding, ${ }^{2}$ \\ Kui J. Zhao, ${ }^{1,3}$ Tina T. X. Dong, ${ }^{1}$ and Karl W. K. Tsim ${ }^{1}$ \\ ${ }^{1}$ Department of Biology and Center for Chinese Medicine, The Hong Kong University of Science and Technology, \\ Clear Water Bay, Hong Kong \\ ${ }^{2}$ Jiangsu Key Laboratory for TCM Formulae Research (LTCMF), Nanjing University of Chinese Medicine, Nanjing 210046, China \\ ${ }^{3}$ Beijing Friendship Hospital, Affiliate of Capital University of Medical Sciences, 95 Yong An Road, Beijing 100050, China
}

Correspondence should be addressed to Karl W. K. Tsim, botsim@ust.hk

Received 7 March 2008; Accepted 17 December 2008

Copyright () 2011 Roy C. Y. Choi et al. This is an open access article distributed under the Creative Commons Attribution License, which permits unrestricted use, distribution, and reproduction in any medium, provided the original work is properly cited.

\begin{abstract}
Danggui Buxue Tang (DBT), a Chinese herbal decoction used to treat ailments in women, contains Radix Astragali (Huangqi; RA) and Radix Angelicae Sinensis (Danggui; RAS). When DBT was applied onto cultured MG-63 cells, an increase of cell proliferation and differentiation of MG-63 cell were revealed: both of these effects were significantly higher in DBT than RA or RAS extract. To search for the biological markers that are specifically regulated by DBT, DNA microarray was used to reveal the gene expression profiling of DBT in MG-63 cells as compared to that of RA- or RAS-treated cells. Amongst 883 DBT-regulated genes, 403 of them are specifically regulated by DBT treatment, including CCL-2, CCL-7, CCL-8, and galectin-9. The signaling cascade of this DBT-regulated gene expression was also elucidated in cultured MG-63 cells. The current results reveal the potential usage of this herbal decoction in treating osteoporosis and suggest the uniqueness of Chinese herbal decoction that requires a well-defined formulation. The DBT-regulated genes in the culture could serve as biological responsive markers for quality assurance of the herbal preparation.
\end{abstract}

\section{Introduction}

Estrogen deficiency is the major cause in developing postmenopausal osteoporosis. Estrogen acts on both osteoblast and osteoclast to inhibit bone breakdown at all stages of life. After menopause, estrogen replacement therapy is an effective treatment for osteoporosis as well as to allay other menopausal symptoms [1]. However, estrogen therapy recently became a subject of debate because clinical studies revealed an increased risk of breast cancer and coronary artery disease in women who take estrogen [2]. In view of these clinical risks, extensive efforts have been devoted to develop different strategies that would yield the benefits of estrogen therapy but with minimal side effects [3]. Herbal medicines, in particular the traditional Chinese medicine, are promising preparations that have fewer side effects [4, 5], and which, indeed, have been used widely for menopausal women as dietary supplements in Asia [6, 7].

Amongst thousands of herbal formulae from traditional Chinese medicine, Danggui Buxue Tang (DBT; a herbal decoction) is a simple combination of two herbs. DBT was first described in Neiwaishang Bianhuo Lun by Li Dongyuan in China in AD 1247. Li described the DBT formula should include: 10 qian of Radix Astragali (Huangqi; RA), roots of Astragalus membranaceus (Fisch.) Bunge or A. membranaceus (Fisch.) Bunge var. mongholicus (Bunge) P.K. Hsiao, and two qian of Radix Angelicae Sinensis (Danggui; RAS), roots of Angelica sinensis (Oliv.) Diels. One qian equals to about $3 \mathrm{~g}$. In preparing $\mathrm{DBT}$, the mixed herbs were recommended to boil in two bowls of water over a moderate heat until the final 
volume was reduced by half [8]. Traditionally, DBT has been prescribed to women in China as a remedy for menopausal symptoms. According to Chinese medicinal theory, the daily intake of DBT could raise the "Q $i$ " and nourish the "Blood" of menopausal women.

Pharmacological results indicated that DBT has the abilities to promote hematopoietic functions: to stimulate cardiovascular circulation; to prevent osteoporosis; to increase anti-oxidation activity, to stimulate immune response and to mimic estrogen effects in the receptor phosphorylation $[8,9]$. Besides, RA and RAS are commonly used in treating the age-related diseases, which have been demonstrated in stimulating bone cell proliferation, increasing bone formation and reducing bone re-sorption in patients [10]. By determining the chemical and biological properties of DBT, the optimized conditions of extraction have been established $[8,9]$, which, interestingly, are in accordance with the weight ratio of $5: 1$ for RA to RAS in the ancient preparation. However, the rationale and action mechanisms for including different herbs in Chinese herbal decoctions had never been fully explained, and more important biological markers are missing in controlling the herbal decoction, which consequently hinders the development of Chinese medicine as disease and disorder remedies. In order to reveal the specific events mediated by DBT in preventing osteoporosis, cell proliferation and differentiation were determined in cultured MG-63 cells (an osteosarcoma cell line). In addition, DNA microarray analysis was used to analyze the gene profiling in MG-63 cells after the treatments of extracts derived from DBT, RA, or RAS. The identified DBT-specific regulated genes in the cell culture could serve as biological responsive markers in quality assurance of DBT and in revealing the action mechanism of this decoction.

\section{Methods}

2.1. Plant Materials and Preparation of DBT. Fresh roots were obtained from China in September to October of 2002: 3-year-old A. membranaceus var. mongholicus from Shanxi and 2-year-old $A$. sinensis from Minxian of Gansu $[11,12]$ Their corresponding vouchers as forms of whole plants, voucher specimens for A. membranaceus var. mongholicus and $A$. sinensis, were deposited in the Department of Biology, The Hong Kong University of Science and Technology, China. In preparing DBT, exact amounts of RAS and RA were weighed according to a ratio of $5: 1$ and then mixed well by vortex. The mixture was boiled in 8 volume of water $(\mathrm{v} / \mathrm{w})$ for $2 \mathrm{~h}$, and extracted twice; this extraction was shown to be the best extracting condition [8]. RAS or RA alone was extracted by the same method. The extracts were dried by lyophilization and stored at $-80^{\circ} \mathrm{C}$.

2.2. Chemical Standarization of DBT. Ferulic acid was purchased from Sigma (St Louis, MO), calycosin, formononetin and ligustilide (z-isoform) were kindly provided by Prof. Pengfei Tu, Medical College of Peking University; their purities, confirmed by HPLC, were $>99.0 \%$. AR and HPLC grade reagents were from Merck (Darmstadt, Germany). The HPLC system consisted of Waters (Milford, MA) 600 pump, 717 auto-sampler and UV/VIS Photodiode Array 2996 Detector were used for all analysis. Chromatographic separations were carried out on a DELTA-PAK $\mathrm{C}_{18}$ column (particle size $4.6 \mu \mathrm{m}, 3.9 \times 150 \mathrm{~mm}$ ) with acetonitrile (as Solvent A): 0.01\% phosphoric acid (as Solvent B) as mobile

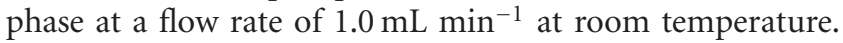
A linear gradient elution was applied from 15 to $65 \%$ of Solvent A starting from 0 to $60 \mathrm{~min}$. Samples were filtered through a $0.45 \mu \mathrm{m}$ Millipore syringe filter unit. A sample of $20 \mathrm{~mL}$ was injected for HPLC analysis. The calibration of these chemicals followed previous reports $[8,9]$.

\subsection{The Cultures of MG-63 Cells and Rat Osteoblasts.} Human osteosarcoma cell line MG-63 was obtained from the American Type Culture Collection (ATCC, Manassas, VA) and was grown in Modified Eagle's medium (MEM), supplemented with $10 \%$ fetal bovine serum, $2 \mathrm{mM}$ L-glutamine, $0.1 \mathrm{mM}$ non-essential amino acids, $1 \mathrm{mM}$ sodium pyruvate, $100 \mathrm{U} \mathrm{mL}^{-1}$ penicillin, and $100 \mu \mathrm{g} \mathrm{mL}^{-1}$ streptomycin in a humidified $\mathrm{CO}_{2}(5 \%)$ incubator at $37^{\circ} \mathrm{C}$. Culture reagents were from Invitrogen (Carlsbad, CA, USA). Before 3 days of the treatment, the medium was changed to MEM- $\alpha$ without phenol red containing $2 \%$ charcoal-dextran-treated fetal bovine serum. MG-63 cells were seeded onto 12well plate or 96-well plate in MEM- $\alpha$ medium. Next day, the medium was replaced by fresh medium containing $1 \mathrm{mg} \mathrm{mL}^{-1}$ DBT, RAS or RA extracts for $48 \mathrm{~h}$. $17 \beta$-Estradiol (Sigma) dissolved in dimethyl sulfoxide (DMSO) was used as a control. For the control vehicle, $0.0001 \%$ DMSO was used. The cell number was determined by a manual cell counting method. In brief, the drug-treated MG-63 cells were detached by treatment with trypsin digestion and resuspended in PBS, and the cell number was counted by a hemocytometer. Besides, a biochemical colorimetric method named 3-(4,5-dimethylthioazol-2-yl)-2,5-diphenyltetrazolium bromide (MTT; Sigma) assay was employed. The absorbance at $570 \mathrm{~nm}$ was measured using an enzyme-linked immunosorbent assay plate reader (Dynatech MR 5000) [13]. A standard curve of cell number against absorbance at $570 \mathrm{~nm}$ was performed. All calibration was done within the linear range of the standard curve. The enzymatic activity of alkaline phosphatase in MG-63 cells was measured by the hydrolysis of $p$-nitrophenyl phosphate as described previously [14]. Briefly, $100 \mu \mathrm{L}$ of the homogenate derived from the drug-treated MG-63 cells was added to the substrate solution, which contained $10 \mathrm{mM}$ p-nitrophenyl phosphate as a substrate in $100 \mathrm{mM}$ diethanolamine buffer ( $\mathrm{pH} 10.5)$ supplemented with $0.5 \mathrm{mM} \mathrm{MgCl} 2$. After $30 \mathrm{~min}$ of incubation at $37^{\circ} \mathrm{C}$, the reaction was terminated by addition of $2 \mathrm{M}$ $\mathrm{NaOH}$, and the activity was determined spectrophotometrically $(410 \mathrm{~nm}$ ) by measuring $p$-nitrophenyl released from the substrate. The enzyme activity was expressed as micromole of substrate cleaved per milligram of cell protein. For the analyses of inhibitors, the cultures were pre-treated with estrogen receptor antagonist ICI $182780(0.1 \mu \mathrm{M}$; Tocris, Ellisville, MO, USA) and Erk1/2 inhibitor U0126 (10 $\mu \mathrm{M}$; Sigma) for $3 \mathrm{~h}$ before the application of other drugs. Phorbol 12 -myristate 13 -acetate $(0.1 \mu \mathrm{M}$; TPA; Sigma) was used as an Erk1/2 activator. 
Primary culture of osteoblasts was performed according to Orriss et al. [15]. In brief, calvarias from postnatal 5-dayold rats were collected and undergone sequential enzymatic digestion: $1 \%$ trypsin for $20 \mathrm{~min}, 0.2 \%$ collagenase for $20 \mathrm{~min}$ and $0.2 \%$ collagenase for $40 \mathrm{~min}$ at $37^{\circ} \mathrm{C}$. After centrifugation at $800 \mathrm{~g}$ for $10 \mathrm{~min}$, supernatant containing osteoblastic cells were collected and maintained in DMEM with $10 \%$ FBS, $2 \mathrm{mM}$ L-glutamine, $0.1 \mathrm{mM}$ non-essential amino acids, $1 \mathrm{mM}$ sodium pyruvate, $100 \mathrm{U} \mathrm{mL}^{-1}$ penicillin, and $100 \mu \mathrm{g} \mathrm{mL} \mathrm{mL}^{-1}$ streptomycin in a humidified $\mathrm{CO}_{2}(5 \%)$ incubator at $37^{\circ} \mathrm{C}$. Cell viability was performed by MTT assay as described before. Osteogenic differentiation was induced by the treatment of vitamin C (250 M) and dexamethasone $(20 \mathrm{nM})$, or by the herbal extracts, for $96 \mathrm{~h}$ and then subjected to total RNA extraction or alkaline phosphatase assay.

2.4. DNA Microarray Analysis. MG-63 cultures were treated $1 \mathrm{mg} \mathrm{mL}^{-1} \mathrm{RA}$, RAS or DBT for $24 \mathrm{~h}$ to extract the total RNAs by TRIzol reagent (Invitrogen). RNA integrity was confirmed by running the formaldehyde-denaturing gel, with purify of ratio A260/280 > 1.8. Total RNAs were subjected to DNA microarray analysis (Chipscreen Biosciences Ltd., Shenzhen, China) to determine the differential gene expressions in treated MG-63 cells. In brief, cDNAs from control and treatment groups were labeled with $\mathrm{Cy} 5$ and Cy3 fluorophores, and hybridized with a DNA microarray chip containing 7458 candidate genes and 384 reference genes. Signals were captured by Generation III array scanner (GE Healthcare, Piscataway, NJ, USA) and data were analyzed by Imagequant 5.0 and Array Vision 6. The significant changes of gene expressions were defined as up-regulation when fluorescent signal in sample was greater than that of control for $200 \%$, or down-regulation when the signal was less than that for $50 \%$.

2.5. Estrogen-Activated Promoter Assay. Three repeats of estrogen responsive elements (ERE: 5'-GGT CAC AGT GAC C- $3^{\prime}$ ) was synthesized as described previously $[9,16]$, and then subcloned into a promoter-reporter vector called pTAL-Luc (Clontech, Mountain View, CA, USA) that has a down stream reporter of firefly luciferase gene; this DNA construct was named as pERE-Luc. Cultured MG-63 cells were transfected with pERE-Luc to generate the stable cell line according to a previous report [17]. Serving as controls, two reporters containing three repeats of responsive elements for myocyte enhancing factor 2 (MEF2; $5^{\prime}$-CTA AAA ATA G-3' in forming pMEF2-Luc) and muscle-regulated transcription factors (MRF; 5' -CAG TTG-3' in forming pE-boxLuc) were constructed in pTA-Luc. Both MEF2 and E-box are muscle-specific gene activation elements. To determine the estrogenic property, different concentration of estrogen, DBT or other extract were applied onto the cultures for $48 \mathrm{~h}$. Afterward, the medium was aspirated, and MG-63 cells were washed by cold PBS. The cells were lysed by a buffer containing $0.2 \%$ Triton X-100, $1 \mathrm{mM}$ dithiothreitol and $100 \mathrm{mM}$ potassium phosphate buffer $\left(\mathrm{pH} \mathrm{7.8)}\right.$ at $4^{\circ} \mathrm{C}$. Followed by centrifugation at $14000 \mathrm{rpm}$ for $4^{\circ} \mathrm{C} 10 \mathrm{~min}$, supernatant was collected and used to perform luciferase assay (Tropix Inc., Bedford, MA, USA); the activity was normalized by equal amount of protein.

2.6. Determination of Phosphorylation. The phosphorylation of extracellular signal-regulated kinases (Erk)1/2 was determined by western blot assay. The cultures were serum starved with or without the inhibitors for $3 \mathrm{~h}$ before the drug applications. After drug treatments, the cultures were collected immediately in lysis buffer $(125 \mathrm{mM}$ Tris$\mathrm{HCl}, 2 \%$ SDS, 10\% glycerol, $200 \mathrm{mM}$ 2-mercaptoethanol, $\mathrm{pH}$ 6.8), and the proteins were subjected to SDS-PAGE analysis. Phosphorylated Erk1/2 were recognized by antiphospho-Erk1/2 antibody (1:5000; Cell Signaling, Danvers, MA, USA) at $4^{\circ} \mathrm{C}$ for $12 \mathrm{~h}$, and horseradish peroxidase (HRP)-conjugated anti-rabbit secondary antibody (1:5000; Invitrogen) for $1 \mathrm{~h}$ at room temperature. The immunocomplexes were visualized by the enhanced chemiluminescence (ECL) method (GE Healthcare). The band intensities, recognized by the antibodies in the ECL film, in control and agonist-stimulated samples were run on the same gel and under strictly standardized ECL conditions. The bands were compared on an image analyzer, using in each case a calibration plot constructed from a parallel gel with serial dilution of one of those samples: this was to ensure the subsaturation of the gel exposure.

2.7. PCR Analysis. MG-63 cells, or primary cultures of rat osteoblasts, with or without inhibitor pre-treatments were treated with $1 \mathrm{mg} \mathrm{mL}^{-1}$ DBT, RA or RAS extract for $12 \mathrm{~h}$. Total RNAs were isolated by TRIzol reagent (Invitrogen), and $5 \mu \mathrm{g}$ of total RNA was reverse-transcribed by Moloney Murine Leukemia Virus Reverse Transcriptase (Invitrogen) according to the manufacturer's instructions. Qualitative PCR was performed to determine the expression of estrogen receptor (ER) $\alpha$ and $\beta$. The primers were: $5^{\prime}$-TGA AGC ACA AGC GTC AGA GA-3' and $5^{\prime}$-CGT AGC CAG CAA CAT GTC AA-3' for ER $\alpha$ (501 bp), 5' -CTC TTG GAG AGC TGT TGG AT- $3^{\prime}$ and $5^{\prime}$-CTG TGA CCA GAG GGT ACA T-3' for $\operatorname{ER} \beta$ (259bp), with conditions of $94^{\circ} \mathrm{C}(1 \mathrm{~min}), 60^{\circ} \mathrm{C}$ $(1 \mathrm{~min})$ and $72^{\circ} \mathrm{C}(1 \mathrm{~min})$ for 30 cycles. The real-time PCR was performed by using SYBR Green Master Mix and Rox reference dye according to the manufacturer's instructions (Applied Bioscience, Foster city, CA, USA). The primers for other transcripts were: 5'-TGT GAT GCC CTT AGA TGT CC-3' and 5' -GAT AGT CAA GTT CGA CCG TC-3' for $18 \mathrm{~S}$ rRNA (320 bp), 5'-TTC ATC ACC ACC ATT CTG GG-3' and $5^{\prime}$-CAT GGG TCA GCT GGA TGT C-3' for galectin-9 (289 bp); 5'-AAG GAG GTC TGT GCT GAC-3' (common chemokine C-C motif; CCL sense primer) and $5^{\prime}$-GAT TCT TGC AAA GAC CCT-3', or 5' -AGA GAA GGG AGG AGC AT-3' or $5^{\prime}$-AGG ATG TAT GAC AGA TAG AG-3' for CCL2 (242 bp), CCL-7 (356 bp) or CCL-8 (364 bp), respectively. SYBR green signal was detected by Mx3000ptm multiplex quantitative PCR machine (Stratagene, La Jolla, CA, USA), with annealing temperature at $60^{\circ} \mathrm{C}$ in all cases. Transcript levels were quantified by using the $\Delta \Delta C_{t}$ value method [18]. Calculation was done by using the $C_{t}$ value of $18 \mathrm{~S}$ rRNA to normalize the $C_{t}$ value of target gene in each sample to obtain the $\Delta C_{t}$ value, which then was used to compare 
among different samples. PCR products were analyzed by gel electrophoresis and melting curve analysis to confirm specific amplifications.

2.8. Other Assays. The protein concentrations were measured routinely by Bradford's method with a kit from Bio-Rad Laboratories (Hercules, CA, USA). Statistical tests were made by the Primer program, version 1 (Primer of Biostatistics): differences from basal or control values (as shown in the plots) were classed as significant $(*)$ where $P$ $<.05,(* *)$ where $P<.01$ and highly significant $(* * *)$ where $P<.001$ by Student's $t$ test.

\section{Results}

3.1. The Osteogenic Properties of DBT in Cultured MG63 Cells. DBT, composed of RA and RAS in a weight ratio of $5: 1$, was prepared according to the optimized extraction conditions as described previously [8]. In order to standardize the herbal extract chemically, we generated HPLC fingerprints: these fingerprints were required as to ensure the chemical composition of DBT, or extracts from RA and RAS, in all pharmacological experiments (Figure 1). By discovering the amounts of two chemical markers in RA (calycosin and formononetin) and two others in RAS (ferulic acid and ligustilide), we were able to standardize the optimal DBT. We found that the standardized DBT should contain $0.186 \mathrm{mg}$ calycosin, $0.155 \mathrm{mg}$ formononetin, $0.351 \mathrm{mg}$ ferulic acid and $0.204 \mathrm{mg}$ ligustilide per $1 \mathrm{~g}$ dried weight of DBT; this was in line to our previous studies $[8,9]$. In addition, a standardized extract of RA in $1 \mathrm{~g}$ should contain $0.088 \mathrm{mg}$ calycosin and $0.142 \mathrm{mg}$ formononetin, while the extract of RAS in $1 \mathrm{~g}$ should have $0.293 \mathrm{mg}$ ferulic acid and $0.316 \mathrm{mg}$ ligustilide. From the calculations of extraction efficiency, the yield of DBT, RA and RAS were in a range from 29 to $32 \% \pm$ $3 \%(n=5)$.

Amongst different effects of DBT in cell cultures, we decided to used cultured bone cells as the study model here; because DBT-induced bone cell differentiation has been described [8]. MG-63 cell, a human cell line that exhibits phenotypic properties of osteoblast is a common cell line used in analyzing bone formation [19]. More importantly, the comparison between MG-63 cells and primary culture of osteoblasts had been done, which showed that the two types of osteoblastic cells shared a close similarity in terms of synthesis and display of glycan structures [20].

By using cell counting and MTT assay, the proliferation of MG-63 cells induced by DBT, RA, RAS, RA + RAS (boiled separately and then mixed together in 5:1 ratio) and estrogen were determined. As shown in Figure 2(a), DBT increased the cell number (from cell counting) and the proliferation (from MTT assay) of MG-63 cells by $\sim 42 \%$ and $\sim 18 \%$, respectively, as compared with the control. This induction effect of cell proliferation was significantly higher than the effects of RA, RAS, or RA + RAS. The positive control, $17 \beta$-estradiol at 10 and $100 \mathrm{nM}$, caused a marked increase in the cell proliferation. The vehicle did not affect the proliferation status of MG-63 cells.

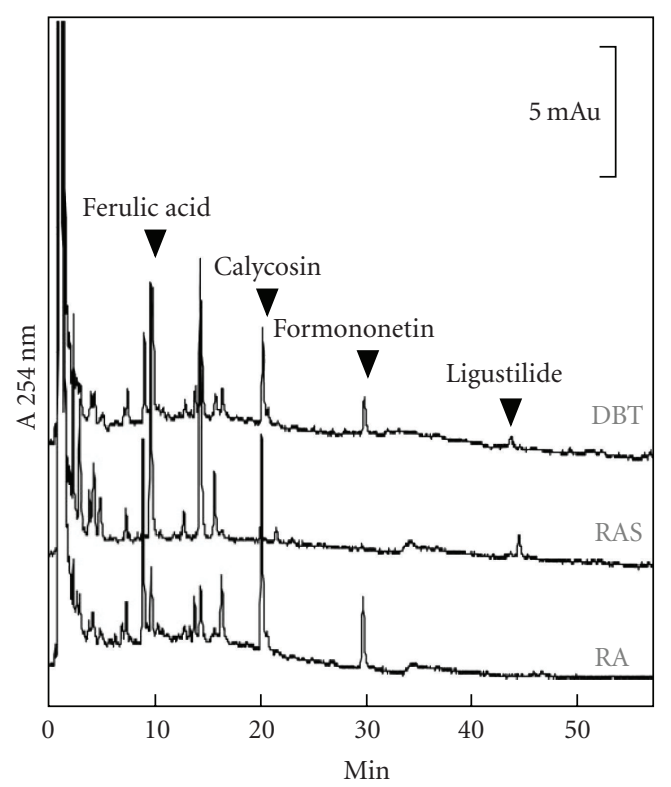

FIgURE 1: Chemical standardization of DBT by HPLC fingerprint analysis. In the HPLC fingerprint at an absorbance of $254 \mathrm{~nm}$, the peaks corresponding to ferulic acid, calycosin, formononetin, and ligustilide in DBT, RA, and RAS are indicated by arrowheads. The details of the marker identification were described previously [8]. These chemical characterizations are used to identify the standardized extracts for all the biochemical analyses. Typical fingerprints are shown.

The increase of alkaline phosphatase activity in MG63 cells occurs at the middle stage of differentiation, which could serve as an indicator of osteoblastic differentiation [21]. Similar to the effect of cell proliferation, DBT induced $22 \%$ increase in alkaline phosphatase activity; this induction was significantly higher than that of RA, RAS or RA + RAS (Figure 2(b)). 17 $\beta$-Estradiol at 10 and $100 \mathrm{nM}$ caused $\sim 6$ and $28 \%$ increase in the enzyme activity. In the DBT-induced cell proliferation and differentiation, the effects of DBT in cultured MG-63 cells were revealed in dose-dependent manners (Figure 2(c)). Both of the assays were rather similar that $0.1 \mathrm{mg} \mathrm{mL} \mathrm{mL}^{-1}$ of DBT showed an induction effect at $\sim 50 \%$.

3.2. Genomic Analysis of DBT-Treated Cells. In a Chinese herbal decoction, we are dealing with multi-components and multi-targets of the pharmacological effects. Lacking a specific biological marker and detail analysis of action mechanism are major obstacle to increase the usage of Chinese medicine. Thus, genomic approach was used here to reveal the gene expression profiling in DBT-treated MG63 cells. The osteoblastic cell line was used here for genomic analysis instead of primary cultured osteoblasts: this was to ensure the consistence of DNA microarray results. The DNA microarray result was summarized in the supplementary table posted in the supplementary information. Figure 3(a) shows a summary of the genomic result. In brief, there are 883 genes are regulated by DBT treatment and 403 are DBT-specific; 660 genes are regulated by RA treatment 


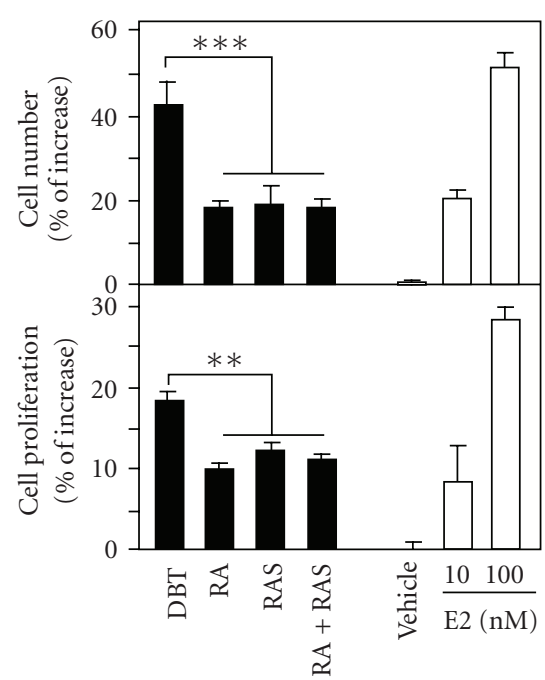

(a)

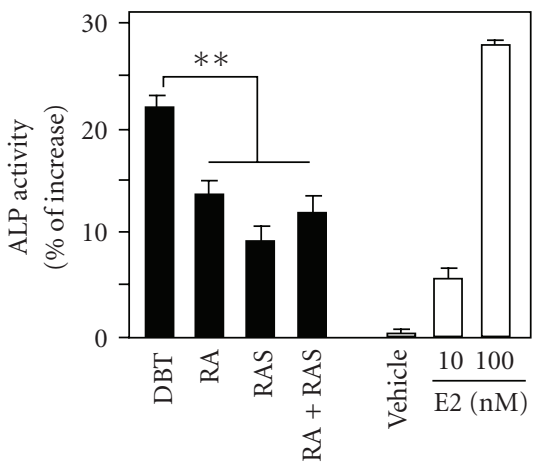

(b)

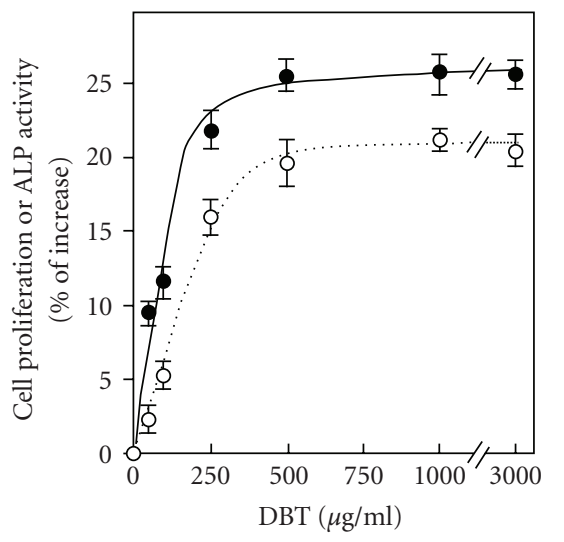

O Proliferation

- ALP activity

(c)

FIGURE 2: DBT increases the cell proliferation and alkaline phosphatase activity in cultured MG-63 cells. (a) Cultured MG-63 cells were treated with extracts $\left(1 \mathrm{mg} \mathrm{mL}^{-1}\right)$ derived from DBT, RA, RAS, and RA + RAS for $48 \mathrm{~h}$ to determine the cell proliferation by cell counting (upper panel) and MTT assay (lower panel). $\beta$-Estradiol (E2; 10 and $100 \mathrm{nM}$ ) was used as a positive control, while $0.0001 \%$ DMSO served as a vehicle. (b) Cultures were treated as in (a) to determine the enzymatic activity of alkaline phosphatase (ALP). (c) A dose-response curve of DBT was performed for both assays as in (a) and (b), with treatment time for $48 \mathrm{~h}$. Values are expressed in percentage of increase as compared with control cultures (without herbal extract), and are in mean \pm SEM, where $n=5$, each with triplicate samples. $* * P<.01$.

and 172 are RA-specific; 1062 genes are regulated by RAS treatment and 473 are RAS-specific. In addition, 279 genes are commonly regulated by the extracts of DBT, RA, and RAS. These numbers already provides us a snapshot that the gene activation of DBT is in distinction to that of a simple addition of RA + RAS extracts.

Amongst the 883 DBT-regulated genes, many of them are known, directly or indirectly, to play roles in bone formation (Table 1). The degree of regulation was varied among different analyzed genes; the highly regulated genes were galectin-9, CCL-8, CCL-7, and CCL-2. Thus, they were selected for validation by quantitative real-time PCR analysis. As expected from the DNA microarray results, the transcripts encoding CCL-2, CCL-7, CCL-8, and galectin-9 were markedly increased by DBT treatment (Figure 3(b)). The transcript expressions of galectin-9, CCL-2, and CCL-8 were increased by 12 - to 17 -folds after the challenge of DBT, while the expression level of CCL-7 mRNA was up regulated with an induction over 50-fold. In line to the result of DNA microarray analysis, the effects of DBT were significantly higher than the extracts derived from RA, RAS or even the simple mixture of RA and RAS, which suggested a strong synergistic effect in combination of RA and RAS and a crucial role of boiling the two herbs together. By comparing the results from the microarray analysis, the transcript induction by the determination of real-time PCR revealed a lower value, which could be accounted by the sensitivity of two different assays. 


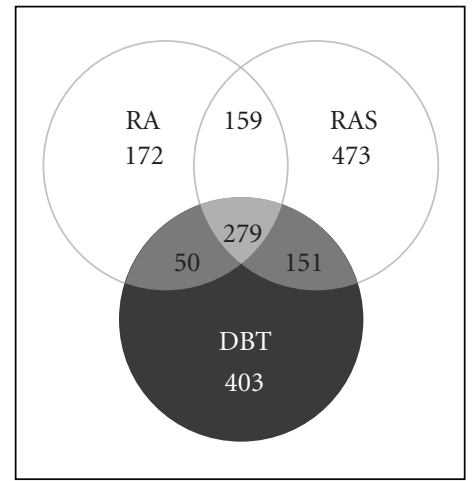

(a)

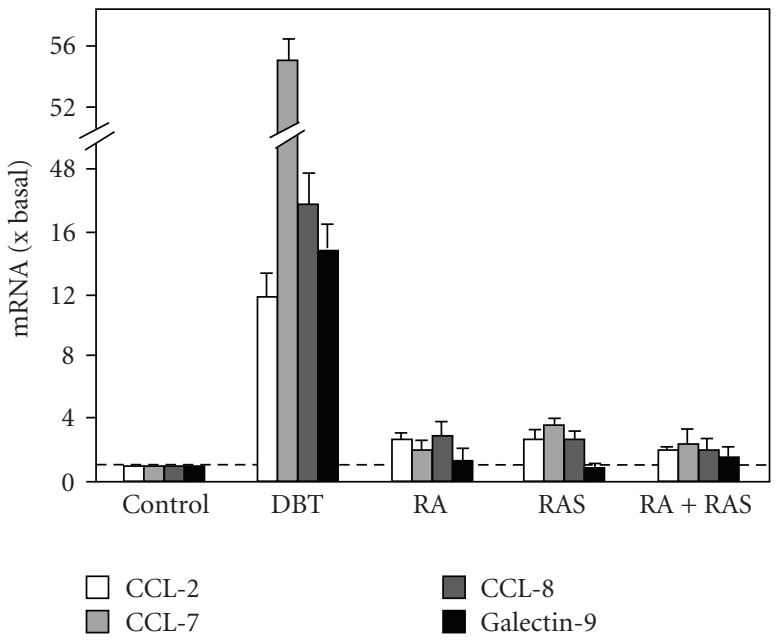

(b)

Figure 3: DNA microarray analysis of DBT-induced specific gene expressions and validation in cultured MG-63 cells. (a) MG-63 cells were treated with $1 \mathrm{mg} \mathrm{mL}^{-1} \mathrm{RA}$, RAS, or DBT for $24 \mathrm{~h}$ and subjected to DNA microarray analysis to determine the differential gene expressions. The DNA chip contained 7458 candidate genes and 384 reference genes: these sequences were derived from human genome. Significant changes of gene expressions were defined as regulated, either up-regulation when fluorescent signal in the sample was greater than that of control for $200 \%$, or down-regulation when the signal was less than that for 50\%. (b) Some of up-regulated genes as in (a) was validated by quantitative real-time PCR analysis. Total RNAs were extracted from cultures treated with different extracts for $24 \mathrm{~h}$ and used to perform real-time PCR analysis to determine the mRNA levels of CCL-2, CCL-7, CCL-8, and galectin-9. Data are normalized by $\Delta \Delta C_{t}$ method using $18 \mathrm{~S}$ rRNA as an internal control, and expressed as the ratio to basal reading where control (without herbal extract) equals to 1 , and in mean \pm SEM, where $n=5$, each with triplicate samples.

TABLE 1: Genes related to bone development are up regulated by DBT.

\begin{tabular}{|c|c|c|c|c|c|}
\hline \multirow{2}{*}{ Regulated gene $^{\mathrm{a}}$} & \multirow{2}{*}{ Symbol } & \multirow{2}{*}{ Genbank no. } & \multicolumn{3}{|c|}{ Fold of change ${ }^{b}$} \\
\hline & & & DBT & RAS & RA \\
\hline Lectin, galactoside-binding, soluble, 9 (Galectin-9) & LGALS9/Gal-9 & AA434102 & 441.76 & 1.60 & 1.77 \\
\hline Small inducible cytokine subfamily A, member 8 & SCYA8/CCL-8 & AI268937 & 184.65 & 2.73 & 2.89 \\
\hline Small inducible cytokine A7 & SCYA7/CCL-7 & AA040170 & 175.02 & 0.33 & 6.96 \\
\hline Small inducible cytokine A2 & SCYA2/CCL-2 & AA425102 & 88.22 & 2.35 & 6.87 \\
\hline Collagen, type XVIII, $\alpha 1$ & COL18 $\alpha 1$ & N81029 & 4.49 & 5.03 & 3.99 \\
\hline Matrix metalloproteinase 9 & MMP9 & T72581 & 3.87 & 5.78 & 7.15 \\
\hline Collagen, type $\mathrm{X}, \alpha 1$ & COL10 $\alpha 1$ & AI828306 & 3.44 & 4.09 & 13.95 \\
\hline Transforming growth factor, $\beta 2$ & TGF $\beta 2$ & AA233738 & 2.60 & 3.40 & 1.77 \\
\hline Insulin-like growth factor 1 & IGF1 & AA456321 & 2.47 & - & - \\
\hline Bone morphogenetic protein 1 & BMP1 & R56774 & 2.29 & 2.88 & 6.66 \\
\hline Epidermal growth factor & EGF & AI480081 & 2.00 & 1.19 & - \\
\hline Integrin, $\alpha 2$ & ITG $\alpha 2$ & AA463257 & 1.87 & 0.75 & 0.85 \\
\hline Msh (Drosophila) homeo box homolog 2 & MSX2 & AA195636 & 1.86 & 1.14 & 0.82 \\
\hline Collagen, type VII, $\alpha 1$ & $\operatorname{COL7} \alpha 1$ & AA598507 & 1.86 & 3.49 & 1.76 \\
\hline Bone morphogenetic protein 6 & BMP6 & AA424833 & 1.73 & 2.28 & 1.27 \\
\hline Msh (Drosophila) homeo box homolog 1 & MSX1 & AA464197 & 1.66 & 1.45 & 1.28 \\
\hline Fibroblast growth factor receptor 3 & FGFR3 & AA419620 & 1.65 & 0.97 & 0.82 \\
\hline Cartilage oligomeric matrix protein & COMP & N94385 & 1.64 & 1.30 & 4.82 \\
\hline Transforming growth factor, $\beta 1$ & TGF $\beta 1$ & R36467 & 1.56 & 1.94 & 2.00 \\
\hline Bone morphogenetic protein 8 & BMP8 & AA779480 & 1.41 & 1.73 & 1.30 \\
\hline Bone morphogenetic protein 7 & BMP7 & W73473 & 1.39 & 1.75 & 1.64 \\
\hline Fibroblast growth factor receptor 1 & FGFR1 & R54846 & 1.36 & 1.17 & 1.25 \\
\hline Multiple inositol polyphosphate phosphatase 1 & MINPP1 & AA161161 & 0.29 & 0.47 & 0.57 \\
\hline
\end{tabular}

${ }^{\mathrm{a}}$ Genes known to play role in bone development are selected for illustration; ${ }^{\mathrm{b}}$ Change of gene expressions as compared to the control (no drug treatment).

“- below detection. 

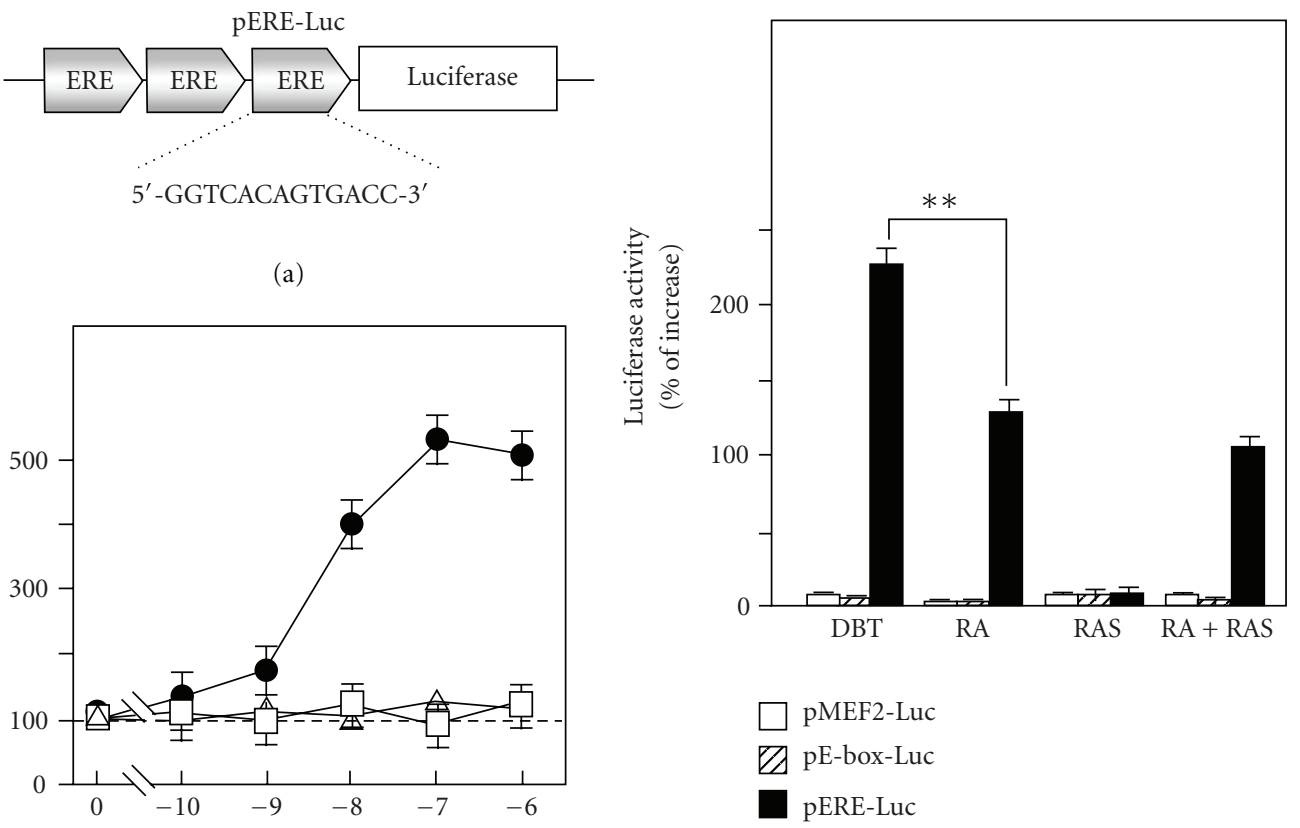

(a)

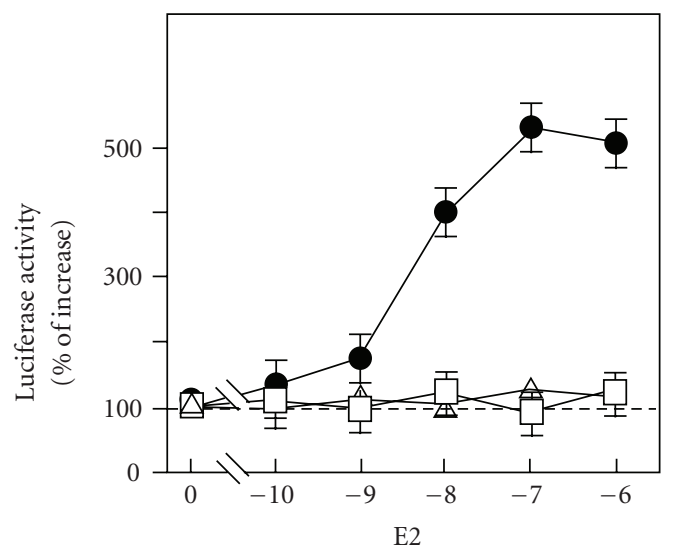

(d)

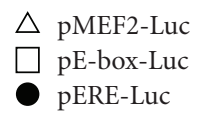

(b)
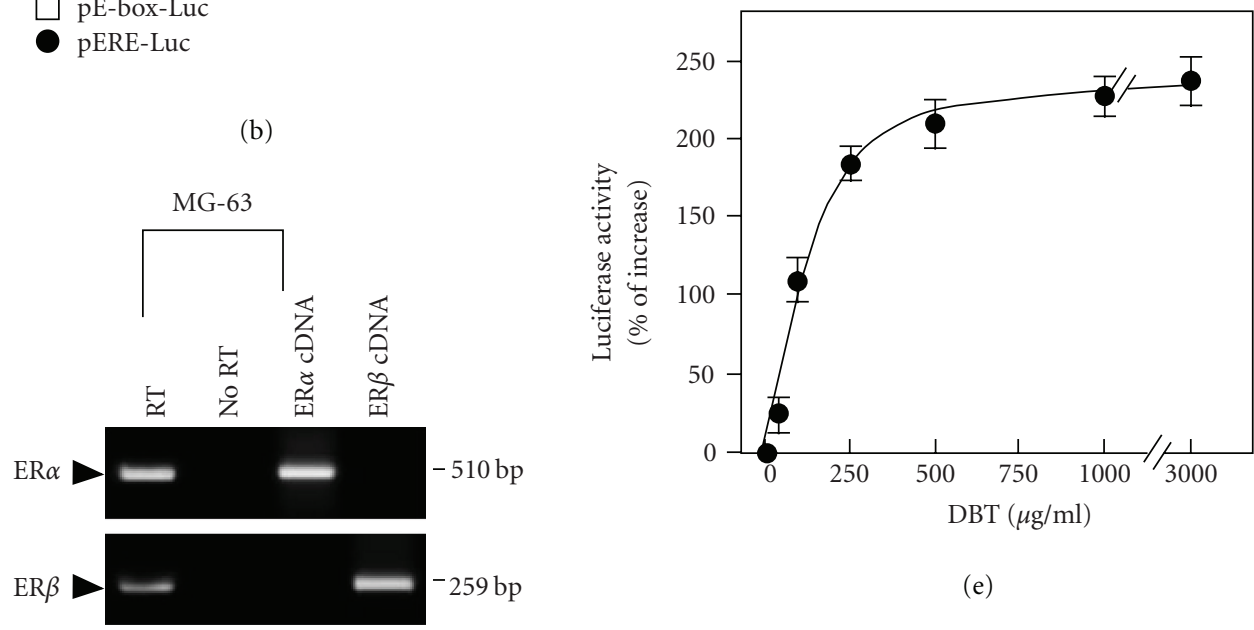

(e)

(c)

FIGURE 4: DBT induces the estrogenic effects in cultured MG-63 cells. (a) Three repeats of estrogen responsive elements (ERE: 5'-GGT CAC AGT GAC C-3') was subcloned into a promoter-reporter vector that has a down stream reporter of firefly luciferase gene, namely as pERE-Luc. (b) Cultured MG-63 cells that stably transfected with pERE-Luc, or transiently transfected with pMEF2-Luc or pE-box-Luc were treated with different concentration of $\beta$-estradiol (E2; from $10 \mathrm{nM}$ to $1 \mu \mathrm{M}$ ) for $48 \mathrm{~h}$ to determine the transcriptional activity of pERE-Luc by luciferase assay. (c) Total RNAs were extracted from MG-63 cells to determine the presence of estrogen receptor $\alpha$ (ER $\alpha$; 510 bp) and $\beta$ $(\mathrm{ER} \beta ; 259 \mathrm{bp})$ by RT-PCR analysis. No RT indicated the absence of contamination by genomic DNA, and ER $\alpha$ and ER $\beta$ cDNAs served as positive control for PCR. Representative images were shown, $n=5$. (d) Cultures were treated with extracts $\left(1 \mathrm{mg} \mathrm{mL}^{-1}\right)$ derived from DBT, RA, RAS and RA + RAS for $48 \mathrm{~h}$ to determine the luciferase activity as in (b). (e) A dose-response curve of DBT was performed as in (b). Values of the promoter-driven luciferase activities are expressed in percentage of increase as compared with control cultures (without herbal extract), and in mean \pm SEM, where $n=5$, each with triplicate samples. ${ }^{* *} P<.01$.

3.3. Signaling Mechanisms of DBT-Specific Gene Regulation. The signaling mechanism of this DBT-induced gene expression was revealed here. DBT has been shown to activate two signaling cascades in different cell types: (i) estrogenic signal; and (ii) mitogen-activated protein (MAP) kinase signal $[9,22]$. In order to test the estrogenic effects of DBT in cultured MG-63 cells, a promoter-reporter construct (pERE-Luc; see Figure 4(a)) containing three repeats of estrogen-responsive element (ERE) was stably transfected into MG-63 cells. Treatment of $17 \beta$-estradiol from $10 \mathrm{nM}$ 


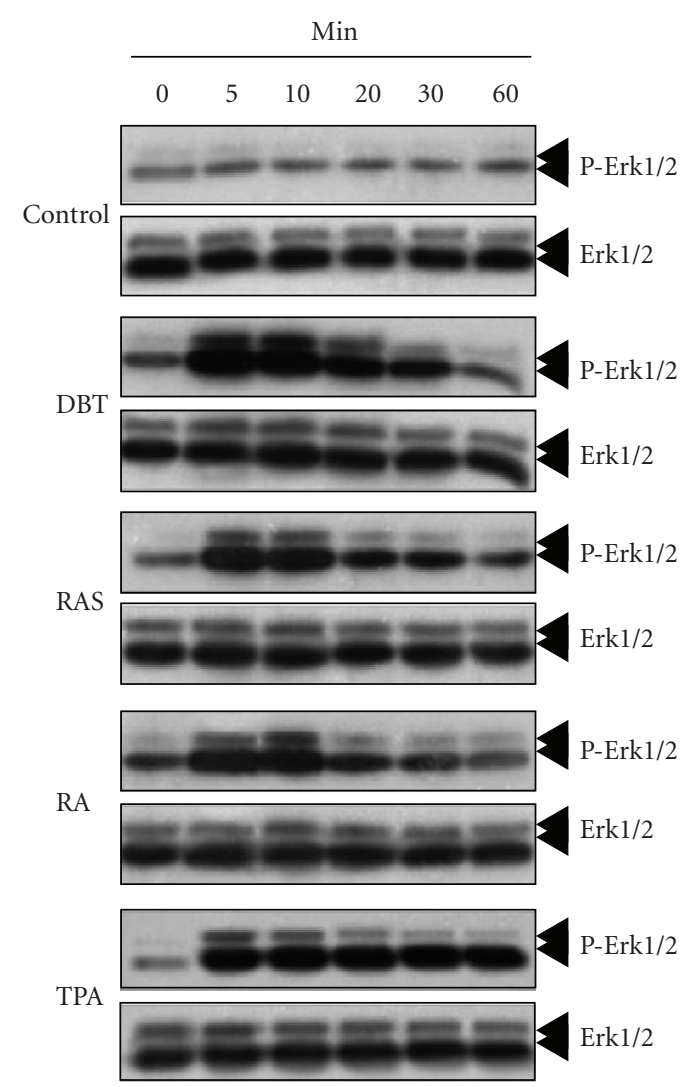

(a)

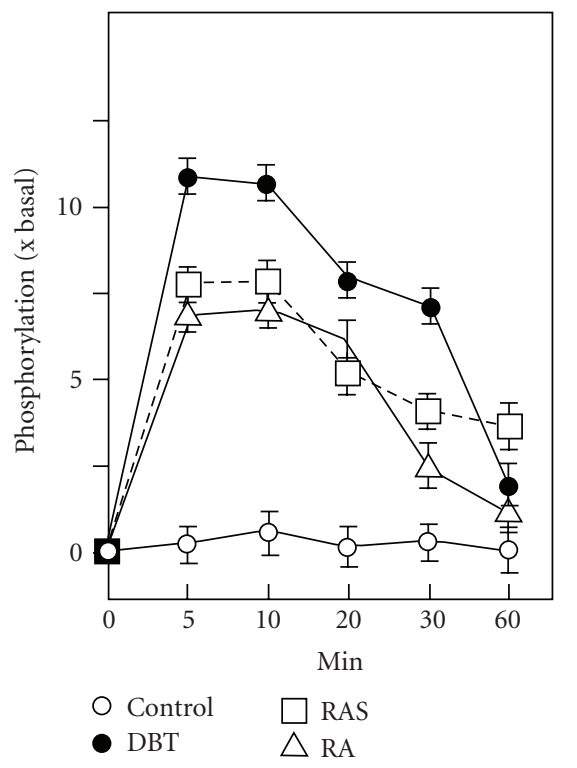

(b)

FIGURE 5: DBT induces Erk1/2 phosphorylation in cultured MG-63 cells. MG-63 cultures were serum starved for $3 \mathrm{~h}$ before the addition of DBT, RA, RAS, and RA + RAS extracts $\left(1 \mathrm{mg} \mathrm{mL}^{-1}\right)$ for different time. Total and phosphorylated inhibitor Erk1/2 and P-Erk1/2 were revealed by western blot analysis using specific antibodies. TPA at $0.1 \mu \mathrm{M}$ served as a control. The lower panel shows the quantitation of phosphorylation from the blots by calibrating the densitometry. Values are expressed as the ratio to basal reading where time 0 equals to 1 , and in mean \pm SEM, where $n=4$.

to $1 \mu \mathrm{M}$ produced a dose-dependent response in activating the activity of pERE-Luc in the stable transfected cell (Figure 4(b)). In contrast, no estrogenic effect was found in either pMEF2-Luc or pE-box-Luc transfected MG-63 cells. Such estrogen-mediated transcriptional activity was further confirmed by the presence of ER $\alpha$ and $\beta$ mRNAs in cultured MG-63 cells (Figure 4(c)). No reverse transcription indicated the absence of contamination by the genomic DNA. The cDNAs encoding ER $\alpha$ and $\operatorname{ER} \beta$ served as positive controls for PCR. These results were consistent with the literature that both $\mathrm{ER} \alpha$ and $\beta$ were present in MG-63 [23, 24]. In addition, the expressions of $\mathrm{ER} \alpha$ and $\beta$ were not altered in our drugtreated cultures.

To test the effect of DBT, different amounts of DBT were applied onto the pERE-Luc-transfected MG-63 cells for 2 days. Application of DBT led to the activation of promoter activity by an increase of $230 \%$ : the potency was the strongest among different herbal extracts being tested (Figure $4(\mathrm{~d})$ ). Application of $1 \mathrm{mg} \mathrm{mL}{ }^{-1} \mathrm{RA}$ or $1 \mathrm{mg} \mathrm{mL} \mathrm{m}^{-1}$ RA + RAS (boiled separately and then mixed together) also induced promoter activity to $\sim 110 \%$; however, the activity was lower when compared with the activity of DBT. RAS $\left(1 \mathrm{mg} \mathrm{mL}^{-1}\right.$ ) did not have any activation effect (Figure $4(\mathrm{~d})$ ).
Showing the specificity of DBT response, the muscle-specific gene responsive elements, MEF2 and E-box, did not respond to the challenge of DBT. In addition, the DBT treatment showed a dose-dependent response in activating pEREdriven luciferase activity (Figure 4(e)). This estrogenic effect of DBT has been shown previously in cultured MCF-7 cells (a breast cancer cell line) and the potency is comparable [9], which indicated the possession of estrogenic property of DBT in cultured MG-63 cells.

MAP kinases are involved in numerous cellular responses including cell growth and differentiation, and they have been shown to participate in estrogenic effects. Therefore, we studied the phosphorylation of Erk1/2, a MAP kinase with an important role in the classical Raf-MEK-Erk pathway. The serum-starved MG-63 cultures were treated with different drugs and collected at different times. The phosphorylations of Erk1 (P-Erk1; $44 \mathrm{kDa}$ ) and Erk2 (P-Erk2; 42 kDa) were markedly increased by the addition of DBT; the activation was transient and peaked at over 10-fold in 5-10 min after the treatment (Figure 5). In comparison to DBT, the phosphorylation of Erk1/2 was also increased by $\sim 7$-fold when MG-63 cells were treated with RA or RAS (Figure 5). As a control, the application of TPA, a known activator of 


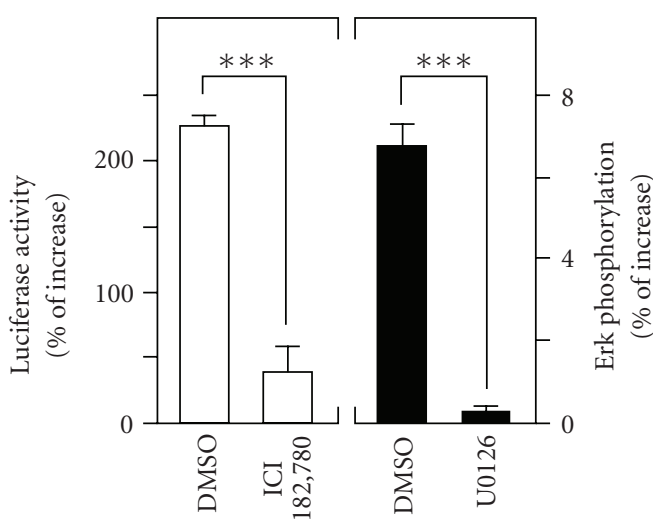

(a)

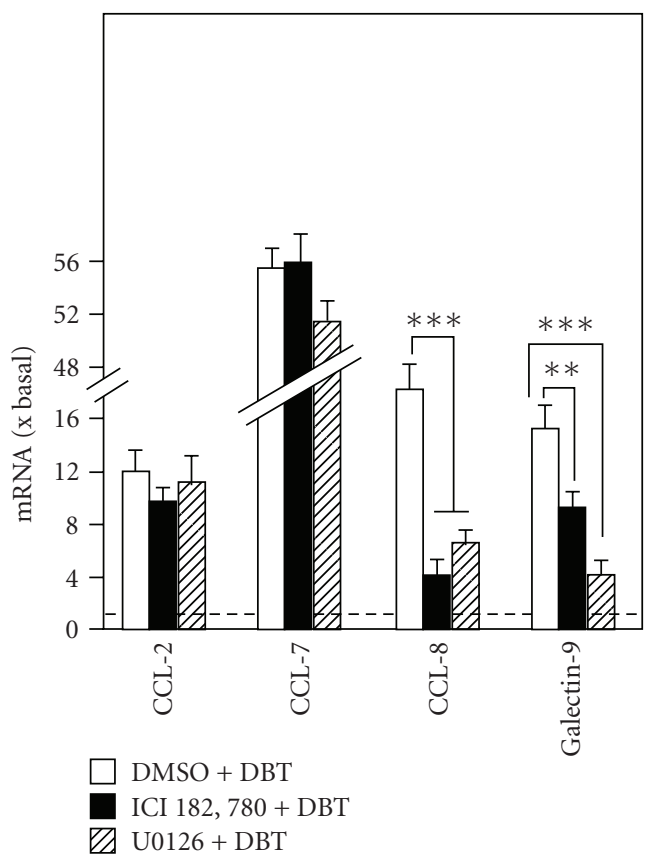

(c)

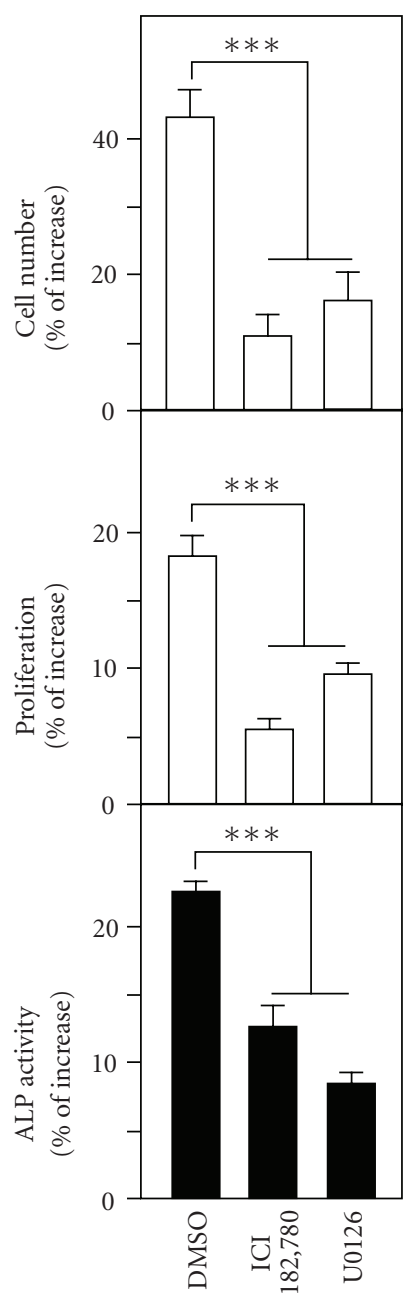

(b)

FIGURE 6: The DBT-induced osteogenic effects and gene expressions are blocked by specific inhibitors. (a) MG-63 cultures stably transfected with pERE-Luc were pre-treated with buffer (0.1\% DMSO; control), ICI 182780 (an ER blocker; $0.1 \mu \mathrm{M}$ ) and U0126 (Erk inhibitor; $10 \mu \mathrm{M}$ ) for $3 \mathrm{~h}$ before the addition of DBT $\left(1 \mathrm{mg} \mathrm{mL}^{-1}\right)$ for $24 \mathrm{~h}$ to determine the luciferase activity driven by ERE activation (left panel) and Erk1/2 phosphorylation at $5 \mathrm{~min}$ (right panel). (b) Cultures were treated for $48 \mathrm{~h}$ as in (a) to determine cell number (by cell counting), cell proliferation (by MTT assay) and alkaline phosphatase (ALP) activity. (c) To investigate the signaling mechanisms of DBT-induced gene expressions, MG-63 cells were pre-treated with inhibitors and then DBT as in (a) for $24 \mathrm{~h}$ to measure the change of CCL-2, CCL-7, CCL8, and galectin-9 mRNA expressions by real-time PCR analysis. Values are expressed in percentage of increase as compared with control cultures (without herbal extract), and in the ratio to basal reading where control (without herbal extract) equals to 1 , mean \pm SEM, where $n$ $=5$, each with triplicate samples. ${ }^{* *} P<.01,{ }^{* * *} P<.001$.

Erk1/2, induced the phosphorylation of Erk1/2 by $\sim 10$-fold in a sustained manner.

To distinguish the role of estrogenic and MAP kinase signalings on DBT-induced effects in MG-63 cells, specific inhibitors for ER and MAP kinase, ICI 182780 and U0126, respectively, were used to test the regulatory effects of DBT. The blocking effects by these inhibitors were shown in Figure 6(a). Cultures were pre-treated with inhibitors, or DMSO (control), for $3 \mathrm{~h}$ before the application of DBT $\left(1 \mathrm{mg} \mathrm{mL} \mathrm{mL}^{-1}\right)$ for 2 days. The DBT-induced
pERE-Luc transcriptional activity was decreased by the pre-treatment of ER blocker ICI 182780 . Besides, the DBTinduced Erk1/2 phosphorylation was reduced by U0126 application (Figure 6(a)). In cultured osteoblastic cells, both of the inhibitors partially blocked the DBT-induced cell proliferation and alkaline phosphatase activity (Figure 6(b)). These pharmacological studies suggested that the activation effects of DBT could be mediated, at least, by two signaling pathways: ER-dependent and Erk-dependent, which could be partially accounted for the regulatory mechanisms of 


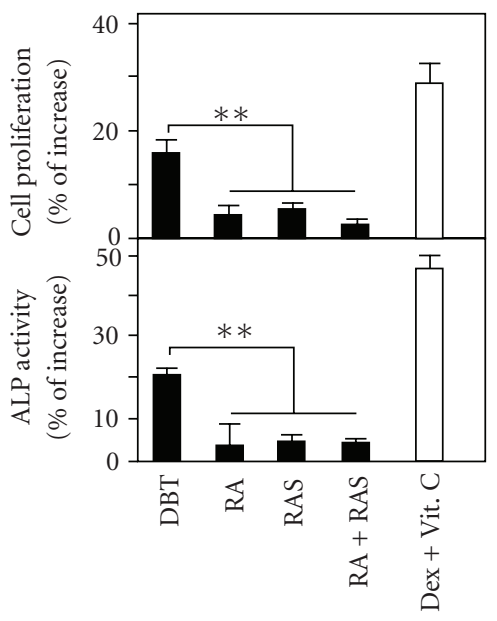

(a)

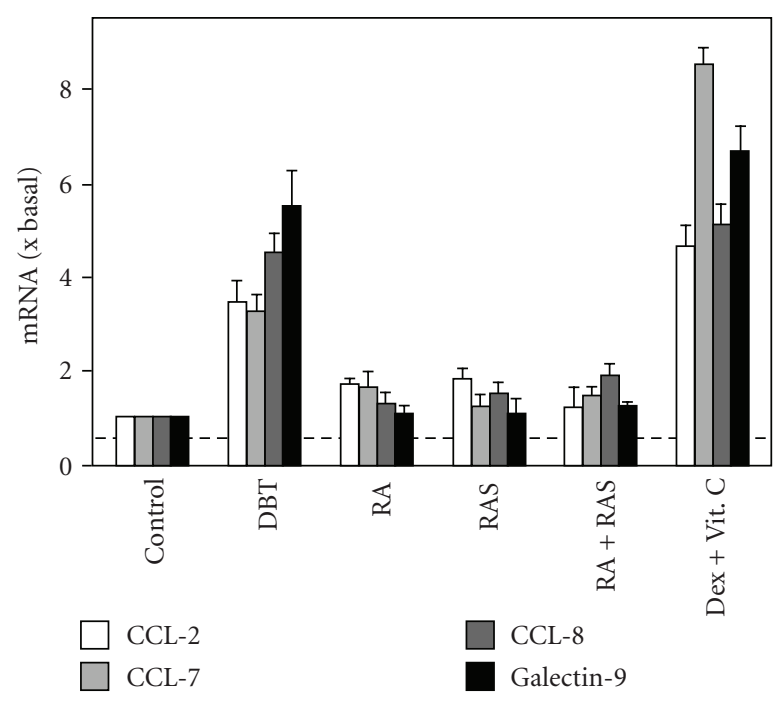

(b)

FIGURE 7: DBT stimulates the osteogenic differentiation of cultured primary osteoblasts. (a) Primary culture of osteoblasts were treated with $1 \mathrm{mg} \mathrm{mL} \mathrm{m}^{-1}$ DBT, RA, RAS, RA + RAS, and Dex + Vitamin C (positive control). After 96-h incubation, cultures were collected to perform cell proliferation and alkaline phosphatase activity assays as in Figure 2. Values are expressed in percentage of increase as compared with control cultures (without herbal extract), and are in mean \pm SEM, where $n=5$, each with triplicate samples. ${ }^{* *} P<.01$. (b) Primary osteoblasts were treated as in (a) for $12 \mathrm{~h}$. Total RNAs were collected to determine the change of CCL-2, CCL-7, CCL-8, and galectin-9 mRNA expressions by real-time PCR analysis as in Figure 3. Data are normalized by $\Delta \Delta C_{t}$ method using $18 \mathrm{~S}$ rRNA as an internal control, and expressed as the ratio to basal reading where the control (without herbal extract) equals to 1 , and in mean \pm SEM, where $n=5$, each with triplicate samples.

DBT in triggering the proliferation and differentiation of osteoblastic cells.

Moreover, the roles of these inhibitors in DBT-regulated genes were also investigated by real-time PCR analysis. Application of the two inhibitors blocked the DBT-induced mRNA expressions in different extent; the blockage of CCL8 was significant with more than $75 \%$ (Figure 6(c)). For galectin-9, the suppression effect of U0126 was greater than ICI 182 780. On the contrary, the DBT-induced CCL-2 and CCL-7 genes were totally unaffected by the two inhibitors (Figure 6(c)). These results suggest the diversity of the DBT-induced downstream signaling in cultured osteoblasts, that is, gene transcription is triggered via distinct signaling cascades.

3.4. Osteogenic Effects of DBT in Rat Osteoblasts. To further support the beneficial roles of DBT on bone development, the primary culture of rat osteoblasts was employed here as another study model. The osteoblastic cultures were treated with different extracts for $96 \mathrm{~h}$ and collected to perform cell proliferation and alkaline phosphatase assays. As expected, DBT increased the cell proliferation and alkaline phosphatase activity by $\sim 20 \%$ (Figure $7(\mathrm{a})$ ), while the effects of RA, RAS or RA + RAS were all $<10 \%$. Dexamethasone and vitamin C (Dex + Vitamin C) served as a positive control for both assays. In addition, the specific gene transcriptions in DBTtreated cultures were determined. The results from real-time PCR analysis indicated that the four target genes, CCL-2, CCL-7, CCL-8, and galectin-9, were stimulated by DBT for at least 4-fold (Figure 7(b)). On the other hand, the change of mRNA levels in RA-, RAS- or RA + RAS-treated osteoblasts were $<2$-fold. These results were consistent with that of MG-63 cells (Figures 2 and 3), which greatly supported the uniqueness of DBT decoction and the beneficial effects of DBT on the osteoblastic cells.

\section{Discussion}

This study, for the first time, demonstrated the trophic roles of an ancient Chinese herbal decoction having a combination of RA and RAS in a weight ratio of $5: 1$ on bone cells. Based on our current results, a brief summary was proposed (Figure 8). According to the ancient formulation, the DBT decoction was prepared by boiling RAS and RA together in 1:5 mass ratio. Application of DBT onto osteoblastic cells triggered the downstream signaling cascades including the Erk-dependent and ER-dependent pathways. Such signaling activations finally resulted in stimulating cell proliferation, osteogenic differentiation and a set of DBT-regulated gene transcription. DBT possesses a better effect in stimulating cell proliferation and differentiation in cultured MG-63 cells and primary osteoblasts, as compared to that of the extracts derived from RA or RAS or RA + RAS (boiled separately and then mixed together in 5:1 ratio). In line to this activation effect, genomic analysis revealed a specific set of genes being regulated by DBT, but not by RA or RAS alone. These results therefore provide evidence of the uniqueness of specific combination of RA and RAS in creating the formulation of DBT. In addition, the insufficient stimulating effect of RA + RAS in cultured MG-63 cells suggests that boiling of the two herbs together is essential; this method of DBT preparation, indeed, has long been recommended by Chinese 

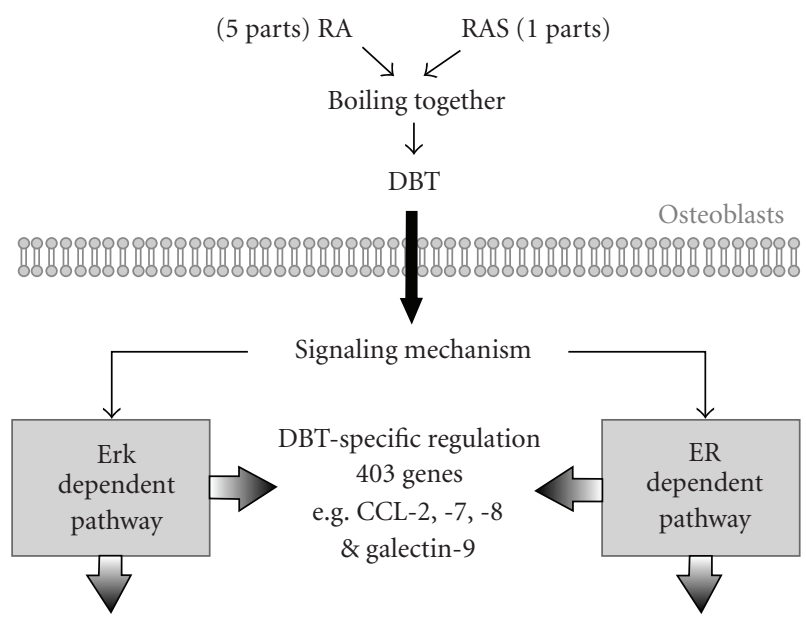

Cell proliferation and osteogenic differentiation

FIGURE 8: Summary for DBT-induced osteogenic effects and specific gene expressions in osteoblastic cells. Application of DBT onto osteoblastic cells triggers the downstream signaling mechanisms including the Erk-dependent and ER-dependent pathways, which may be mediated directly by DBT or indirectly by a receptor(s) on plasma membrane. Such signaling activations finally result in stimulating cell proliferation, osteogenic differentiation, and a set of specific gene transcriptions.

medicinal practitioners. Although the concentration of DBT in cell culture may not be relevant to that of the effective concentration in animal, the effects of DBT at $\mathrm{mg} \mathrm{mL}^{-1}$ have been shown to be highly significant in different cell types $[8,9,25]$. In addition, the oral administration of DBT at a concentration of $\mathrm{g} / \mathrm{kg}$ could markedly affect the oxidative status of rat [26]. Thus the biological properties of this 800 year-old decoction, as demonstrated in our previous studies and here, have been revealed in both cell culture and animal studies.

The author of DBT Li Dongyuan wrote down the formulation and the preparation methods probably based on accumulated experience in clinical application. As proposed by the author, the stimulation of "Qi" and "Blood" are the two critical effects of DBT to keep our body in a healthy balanced state. However, how this herbal decoction could be explained by modern science is not determined. We offer two hypotheses to explain the unique biological function of DBT. First, DBT might contain additional chemicals than those in the extracts of RA or RAS alone. Very likely, these additional chemicals are soluble only in DBT, that is, the boiling of RA and RAS together enhances the solubility of the chemicals. The additional chemicals could be responsible for the distinct DBT-specific effects. Unfortunately, the chemical fingerprint of DBT in our detection method (as in Figure 1) does not show any additional chemicals as compared to that of RA and RAS. Thus, the additional chemicals, if any, could be those that are not detected by HPLC, for example, polysaccharide. The optimized ratio of the two herbs in yielding more active ingredients can be another good explanation for the DBT-specific effects. Our chemical analyses showed that higher amounts of RA-derived astragaloside IV, calycosin, formononetin, and RAS-derived ferulic acid were found in the DBT decoction [8]. Second, there could be a synergistic effect of different components in DBT; this synergistic effect is not present in the extracts of the single herbs. Unfortunately, we do not have direct evidence to test these hypotheses from our DBT experiments. However, because of the failure of the RA + RAS mixture to perform the same functions as DBT, we believe that the second hypothesis is less likely.

By using cultured MG-63 osteoblasts, the gene expression profiling, after the DBT treatment, was revealed. Such DBTregulated gene transcription was further validated in the primary culture of rat osteoblasts. The genomic analysis can reveal not only the activation effect of DBT in stimulating the proliferation and the differentiation in osteoblasts but also a set of biological responsive markers that are specifically triggered by DBT. The specific biomarkers could help to resolve the action mechanism of DBT. For instance, galectin9, a $\beta$-galactoside-binding protein, expresses in various tissues that has implication in modulating cell-cell and cellmatrix interaction [27]. In addition, the role of galectin9 in bone development was revealed to induce osteoblast proliferation through the c-Src/Erk signaling pathway [28]. CCL-2, CCL-7, and CCL-8 also called monocyte chemotactic protein 1 (MCP-1), MCP-3, and MCP-2, respectively, are specifically activated in osteoblast by DBT: they are important chemokines that belong to the CC chemokine super-family and play a critical role in the recruitment and activation of leukocytes $[29,30]$. Because leukocytes produce factors capable of modulating the activities of osteoclast and osteoblast; their recruitment is representing a significant event in regulating osseous metabolism.

The regulatory effects of estrogen in MG-63 osteoblastlike cells were demonstrated previously [31]. By using anti-sense method, estrogen was shown to increase the expressions of collagen and alkaline phosphatase via an ER $\beta$. In line to the anti-sense study, the matrix secretion and cell proliferation of cultured bone cells were abolished in the absence of $\mathrm{ER} \beta$. In addition, $\mathrm{ER} \alpha$ is also proposed to have a role in bone development since both ER $\alpha$ and ER $\beta$ are expressed in MG-63 cells, and ER $\alpha$ has been shown to play a vital role in mediating the osteogenic activities [32]. Therefore, these different lines of evidence further supported the close relationship between estrogen and MG-63 cell proliferation. However, the estrogenic effect in MG-63 cells is very different to that of DBT. These differences include a distinct gene profiling in gene chip analyses between estrogen and DBT and the insignificant changes of galectin-8, CCL2, CCL-7, and CCL-8 after estrogen application in MG-63 cell cultures (data not shown). Although the ER blocker ICI 182780 shows partial blockage of DBT-induced osteogenic effects, this result still supports the estrogenic role of DBT, because the dose of ICI 182780 used is expected to have only $\sim 20 \%$ inhibition on the possible ER binding. Moreover, our preliminary studies by using inhibitors for MAP kinase suggest that the DBT-induced gene activations could be mediated by different signaling mechanisms. This observation is in accordance with the possibilities of having multi-targets of the pharmacological properties of Chinese herbal decoction. 
It is well known that steroid hormones, especially estrogen, can induce the cell proliferation and subsequently leads to an increase risk of developing breast cancer. Indeed, this issue is a major concern of estrogen replacement therapy for the menopausal women. In contrast, DBT could be developed as alternative medicines for the patients. The reasons for this notion include: (i) DBT has been used over 800 years in China, which has been proven to be safe for human; (ii) DBT does not alter the proliferation of the breast cancer cells, even at higher concentration $[8,9]$; (iii) DBT improves biochemical and physiological responses, both in vitro $[9,22]$ and in vivo $[26,33,34]$ that are related to menopausal women. In developing DBT as drug for menopausal women, here we provide the essential elements in searching the chemical and biological markers for this decoction, that is, to have a well-controlled herbal decoction for drug development.

\section{Acknowledgments}

The research was supported by grants from University Grants Committee (AoE/B-10/01) and Research Grants Council (HKUST6419/06M, 662407 and N_HKUST629/07) of the Hong Kong SAR, and Jiangsu Key Laboratory for TCM Formulae Research (LTCMF) Nanjing University of Chinese Medicine (FJK 2006011) to K.W.K.T. K.W.K.T. held a visiting professorship at School of Pharmaceutical Sciences, Peking University in 2005.

\section{References}

[1] K. C. Nichols, L. Schenkel, and H. Benson, "17 $\beta$-Estradiol for postmenopausal estrogen replacement therapy," Obstetrical and Gynecological Survey, vol. 39, no. 4, pp. 230-245, 1984.

[2] V. Beral, E. Banks, G. Reeves, and P. Appleby, "Use of HRT and the subsequent risk of cancer," Journal of Epidemiology and Biostatistics, vol. 4, no. 3, pp. 191-210, 1999.

[3] A. Brzezinski and A. Debi, "Phytoestrogens: the 'natural' selective estrogen receptor modulators?" European Journal of Obstetrics Gynecology and Reproductive Biology, vol. 85, no. 1, pp. 47-51, 1999.

[4] M. G. Glazier and M. A. Bowman, "A review of the evidence for the use of phytoestrogens as a replacement for traditional estrogen replacement therapy," Archives of Internal Medicine, vol. 161, no. 9, pp. 1161-1172, 2001.

[5] F. Xie, C.-F. Wu, W.-P. Lai et al., "The osteoprotective effect of Herba epimedii (HEP) extract in vivo and in vitro," EvidenceBased Complementary and Alternative Medicine, vol. 2, no. 3, pp. 353-361, 2005.

[6] S. E. Geller and F. Kronenberg, "Toward optimal health: the experts discuss the use of botanicals by women," Journal of Women's Health, vol. 12, pp. 847-852, 2003.

[7] G. Calapai and A. P. Caputi, "Herbal medicines: can we do without pharmacologist?" Evidence-Based Complementary and Alternative Medicine, vol. 4, no. 1, pp. 41-43, 2007.

[8] T. T. X. Dong, K. J. Zhao, Q. T. Gao et al., "Chemical and biological assessment of a Chinese herbal decoction containing Radix Astragali and Radix Angelicae Sinensis: determination of drug ratio in having optimized properties," Journal of Agricultural and Food Chemistry, vol. 54, no. 7, pp. 2767-2774, 2006.
[9] Q. T. Gao, J. K. H. Cheung, J. Li et al., "A Chinese herbal decoction, Danggui Buxue Tang, activates extracellular signalregulated kinase in cultured T-lymphocytes," FEBS Letters, vol. 581, no. 26, pp. 5087-5093, 2007.

[10] Q. Yang, S. M. Populo, J. Zhang, G. Yang, and H. Kodama, "Effect of Angelica sinensis on the proliferation of human bone cells," Clinica Chimica Acta, vol. 324, no. 1-2, pp. 89-97, 2002.

[11] X. Q. Ma, Q. Shi, J. A. Duan, T. T. X. Dong, and K. W. K. Tsim, "Chemical analysis of Radix Astragali (Huangqi) in China: a comparison with its adulterants and seasonal variations," Journal of Agricultural and Food Chemistry, vol. 50, no. 17, pp. 4861-4866, 2002.

[12] K. J. Zhao, T. T. X. Dong, P. F. Tu, Z. H. Song, C. K. Lo, and K. W. K. Tsim, "Molecular genetic and chemical assessment of radix Angelica (Danggui) in China," Journal of Agricultural and Food Chemistry, vol. 51, no. 9, pp. 2576-2583, 2003.

[13] K. M. Wright and J. S. Friedland, "Regulation of chemokine gene expression and secretion in Staphylococcus aureusinfected osteoblasts," Microbes and Infection, vol. 6, no. 9, pp. 844-852, 2004.

[14] K. J. Ibbotson, J. Harrod, M. Gowen et al., "Human recombinant transforming growth factor alpha stimulates bone resorption and inhibits formation in vitro," Proceedings of the National Academy of Sciences of the United States of America, vol. 83, pp. 2228-2232, 1986.

[15] I. R. Orriss, G. E. Knight, S. Ranasinghe, G. Burnstock, and T. R. Arnett, "Osteoblast responses to nucleotides increase during differentiation," Bone, vol. 39, no. 2, pp. 300-309, 2006.

[16] C. M. Klinge, "Estrogen receptor interaction with estrogen response elements," Nucleic Acids Research, vol. 29, no. 14, pp. 2905-2919, 2001.

[17] E. K. K. Tung, R. C. Y. Choi, N. L. Siow et al., "P2Y2 receptor activation regulates the expression of acetylcholinesterase and acetylcholine receptor genes at vertebrate neuromuscular junctions," Molecular Pharmacology, vol. 66, no. 4, pp. 794806, 2004.

[18] J. Winer, C. K. S. Jung, I. Shackel, and P. M. Williams, "Development and validation of real-time quantitative reverse transcriptase-polymerase chain reaction for monitoring gene expression in cardiac myocytes in vitro," Analytical Biochemistry, vol. 270, no. 1, pp. 41-49, 1999.

[19] Z. Schwartz, C. H. Lohmann, J. Oefinger, L. F. Bonewald, D. D. Dean, and B. D. Boyan, "Implant surface characteristics modulate differentiation behavior of cells in the osteoblastic lineage," Advances in Dental Research, vol. 13, pp. 38-48, 1999.

[20] X. Yang, J. Yip, M. Harrison, and I. Brockhausen, "Primary human osteoblasts and bone cancer cells as models to study glycodynamics in bone," International Journal of Biochemistry and Cell Biology, vol. 40, no. 3, pp. 471-483, 2008.

[21] J. E. Aubin, F. Lui, L. Malaval, and A. K. Gupta, "Osteoblast and chondroblast differentiation," Bone, vol. 17, no. 2, pp. 77S-83S, 1995.

[22] Q. T. Gao, J. K. H. Cheung, J. Li et al., "A Chinese herbal decoction, Danggui Buxue Tang, prepared from Radix Astragali and Radix Angelicae Sinensis stimulates the immune responses," Planta Medica, vol. 72, no. 13, pp. 1227-1231, 2006.

[23] D. Lu and V. Giguère, "Requirement of Ras-dependent pathways for activation of the transforming growth factor $\beta 3$ promoter by estradiol," Endocrinology, vol. 142, no. 2, pp. 751759, 2001.

[24] E. Lambertini, L. Penolazzi, G. Aguiari et al., "Osteoblastic differentiation induced by transcription factor decoy 
against estrogen receptor $\alpha$ gene," Biochemical and Biophysical Research Communications, vol. 292, no. 3, pp. 761-770, 2002.

[25] Q. T. Gao, J. K. H. Cheung, R. C. Y. Choi et al., "A Chinese herbal decoction prepared from Radix Astragali and Radix Angelicae Sinensis induces the expression of erythropoietin in cultured Hep3B cells," Planta Medica, vol. 74, no. 4, pp. 392395, 2008.

[26] Y. C. Po, Y. L. Hoi, A. H.Y. Siu et al., "Dang-Gui Buxue Tang Protects against oxidant injury by enhancing cellular glutathione in H9c2 cells: role of glutathione synthesis and regeneration," Planta Medica, vol. 73, no. 2, pp. 134-141, 2007.

[27] M. Hirashima, Y. Kashio, N. Nishi et al., "Galectin-9 in physiological and pathological conditions," Glycoconjugate Journal, vol. 19, no. 7-9, pp. 593-600, 2002.

[28] R. Tanikawa, T. Tanikawa, Y. Okada et al., "Interaction of galectin-9 with lipid rafts induces osteoblast proliferation through the c-Src/ERK signaling pathway," Journal of Bone and Mineral Research, vol. 23, no. 2, pp. 278-286, 2008.

[29] J. Van Damme, P. Proost, J. P. Lenaerts, and G. Opdenakker, "Structural and functional identification of two human, tumor-derived monocyte chemotactic proteins (MCP-2 and MCP-3) belonging to the chemokine family," The Journal of Experimental Medicine, vol. 176, pp. 59-65, 1992.

[30] D. T. Graves, Y. Jiang, and A. J. Valente, "The expression of monocyte chemoattractant protein-1 and other chemokines by osteoblasts," Frontiers in Bioscience, vol. 4, pp. D571-D580, 1999.

[31] L. Cao, R. Bu, J. I. Oakley, S. E. Kalla, and H. C. Blair, "Estrogen receptor- $\beta$ modulates synthesis of bone matrix proteins in human osteoblast-like MG63 cells," Journal of Cellular Biochemistry, vol. 89, no. 1, pp. 152-164, 2003.

[32] T. Nakamura, Y. Imai, T. Matsumoto et al., "Estrogen prevents bone loss via estrogen receptor $\alpha$ and induction of fas ligand in osteoclasts," Cell, vol. 130, no. 5, pp. 811-823, 2007.

[33] D. Z. Wu, C. Q. Song, Z. F. Hen, J. L. Kong, Y. Fan, and Z. B. Hu, "Effects of Angelicae sinensis decoction for supplementing blood on the cardiac function in myocardial ischemia reperfusion injury of rats," Pharmacology, Chinese Clinical Materia Medica, vol. 15, pp. 3-6, 1999.

[34] L. Ning, C. X. Chen, R. M. Jin et al., "Effect of components of dang-gui-bu-xue decoction on hematopenia," China Journal of Chinese Materia Medica, vol. 27, no. 1, pp. 50-53, 2002. 


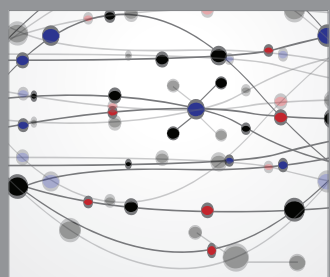

The Scientific World Journal
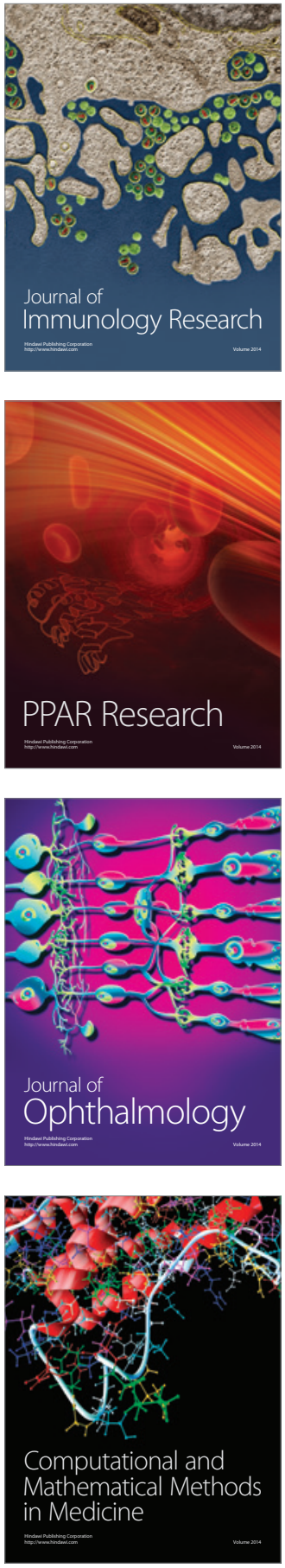

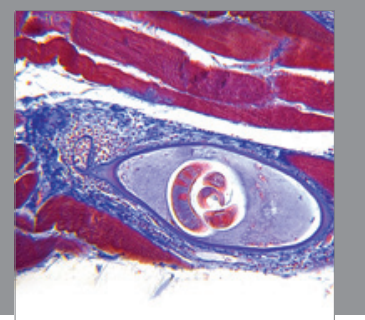

Gastroenterology

Research and Practice
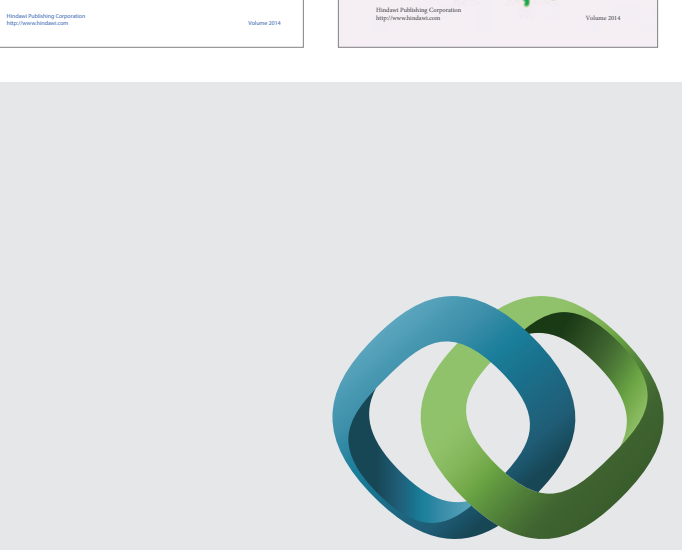

\section{Hindawi}

Submit your manuscripts at

http://www.hindawi.com
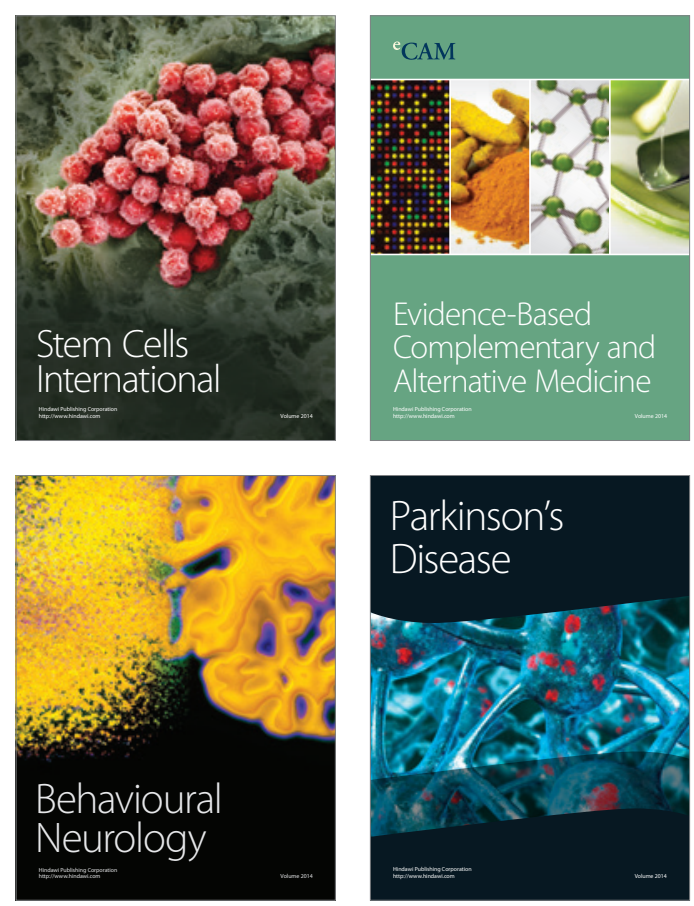

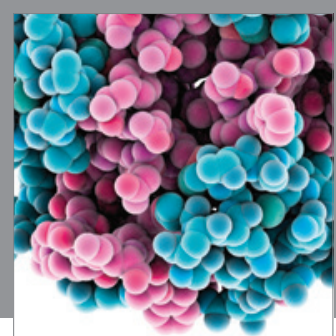

Journal of
Diabetes Research

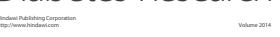

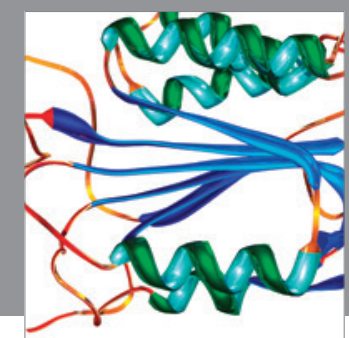

Disease Markers
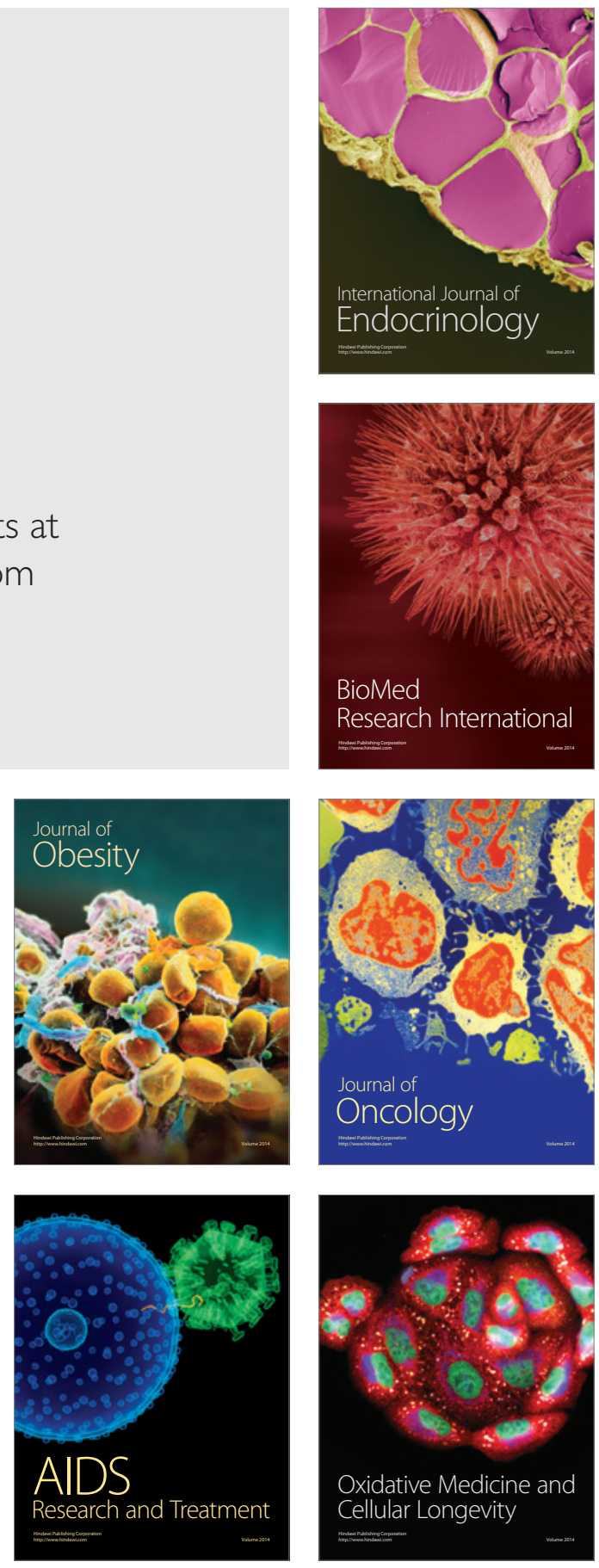